\title{
Subject's rational cognitive activity in the theory of self-organization and epistemological constructivism
}

\author{
Naira Danielyan \\ Department of Philosophy and Sociology, National Research Institute of Electronic Technology, Zelenograd, Moscow, 124498 Russian \\ Federation
}

\section{Email address: \\ vend22@yandex.ru}

\section{To cite this article:}

Naira Danielyan. Subject's Rational Cognitive Activity in the Theory of Self-Organization and Epistemological Constructivism. International Journal of Philosophy. Vol. 1, No. 4, 2013, pp. 51-56. doi: 10.11648/j.ijp.20130104.11

\begin{abstract}
The author provides a comparative analysis of the approach to cognition in the theory of self-organization and radical constructivism from the position of synergy between man and nature. It is advanced the idea on the basis of radical constructivism representatives' concepts by such authors as H. von Foerster, H. Maturana, F. Varela, N. Luhmann, F. Wallner that epistemological subject should be considered as a complex self-organizing object. Its cognitive activity takes place according to the logics of synergetic models. The author proves that cognition based on the constructive realism is the most appropriate to the modern stage of epistemology development as it cancels the opposition of constructivism and realism to some extent as the cognition process from synergetic point of view is an act of projective and constructive thinking which is open for further criticism.
\end{abstract}

Keywords: Epistemological Subject, Epistemological Object, Radical Constructivism, Constructive Realism, Self Organization, Synergy, Anthropic Principle

\section{Constructivism as a Direction in Philosophical Thinking}

\subsection{Three Basic Characteristics of Modern Constructivism}

Let's consider the theory of constructivism in connection with the theory of self-organization. According to I.T. Kasavin, we can consider three basic notions which characterize modern constructivism. They are goal-setting, reasoning and creativity (Kasavin 2008). Following this position and taking into consideration that construction activity is a universal mechanism of forming and developing nature and society, it's possible to substantiate creative-constructive activity of epistemological subject. It should be learnt in such a context as the development of what have existed in nature for ages and a man has been doing it in his own way. However, from the other side we can suppose that construction activity is a unique feature of human consciousness. In this case the world could be shared on passive reality which should be transformed and a man who is realizing this transformation. But there rises a question about the limits of such construction activity, i.e. a man meets the problem of choice: which of the two positions is closer to him? According to the first one, his transformation activity takes its roots in natural processes of self-organization. So, a man isn't responsible for his construction activity. Following the second position, risk and responsibility for construction activity are inevitable features which should always be taken into attention.

\subsection{Constructivism and Anthropic Principle}

It's reasonable to suggest such a system of science construction which allows for anthropic principle in some extent. According to this principle, all objects can't exist without epistemological subject as the world can't be comprehended in general without subject. It means that the basic criterion to estimate every step of subject's epistemological activity is its orientation on philosophical and humanistic principles. It's interesting to note that anthropic principle manifests itself in producing new ways to understand human nature, in special interest to problems of personal autonomy, in searching an integral approach to this problem decision. It is supposed that a man could be studied as a complex self-organizing object by means of synergy. Besides, it is possible to notice that his cognition activity occurs in correspondence with logics of synergetic models. As a result, the horizons of rationality widen and become diluted. That leads to some changes in a man 
conception which is connected with specifying his place in the world. Human cognition comes to the conclusion that the process of self-organization requires a goal-directed character while confirming synergism of a man and the world, i.e. "man's new dialogue with nature" takes place (Prigogine, Stengers 2001). So, a man should be perceived as a process, a whole, but not as a 'thing' (Gurevich 1993). That's why communication, dialogue and researcher's role amplification in the modern epistemology are being studied in the first turn nowadays. Analysis of anthropic principle leads to the conclusion that a non-linear situation doesn't control subject, but it is settled by itself and takes part in subject construction. I'd like to add that any system including the society isn't secured from contingencies, nonlinear situations, i.e. synergetic transformations. As a result, mankind will be responsible for its construction activity instead of the anthropocentric position that has existed so far.

\subsection{Constructing Epistemological Subject and Object in the Theory of Self-Organization}

The scientific model of the reality becomes a result of interaction between a subject of scientific and cognitive activities and the reality. All the information which the subject of rational and cognitive activity can consider as a basis of the reality, e.g. cumulative empiric data, logic norms of a reasoning process, methodological rules and methods, existing theoretical schemes and models, is the necessary, but not enough material to take definite decisions while choosing a way of actions for the given problem situation. As a result, the subject itself is responsible for the choice from a number of alternatives, spectrums of abilities. Unlike the classic science which was directed to ascertaining some fact, the modern science is oriented to an act of project and constructive thinking being opened for further critics. Hence, such kind of activity supposes freedom and creative work.

Modern methodological perception defines this inviolable thesis in two basic directions (Ogurcov 2008). First, these initial aims and presuppositions have not only a cognitive character. They define the whole motivation and semantic structure of subjects of scientific and cognitive activity. It includes factors of integral perception determined socially and culturally. It's necessary to notice that the theses about social and cultural determination of science and its value importance are stressed in the modern philosophy of science strenuously (Encyclopedia of epistemology and philosophy of science 2009). But it's obvious that influence of motivation and semantic factors of subjectivity on cognitive aims should be considered rather widely taking into account individual mental features, different personal preferences, etc. Second, understanding originality and specific positions of different subjects of scientific and cognitive activity according to aims of motivation and semantic spheres of the subjects' perception, this activity should be introduced as a complex process of interaction among different positions, research programs, etc.

The development of scientific reflection in the above directions inevitably leads to understanding the fact that the modern scientific picture of the world can be formed and perceived sufficiently only by means of the 'open' rationality while using abilities of rational and reflexive perception. The 'open' rationality supposes an ability to leave the limits of a fixed system of initial cognitive coordinates and the limits of hard constructions having a prescribed initial sense, some presuppositions and concepts. Thus, the 'open' rationality is aimed at the development of personal cognitive abilities, broadening someone's horizons in his reality perception, constructing a scientific picture of the world as close to the reality as it's possible. Consequently, the reality reflection in its originality can be realized only in the dynamics of collision and mutual enrichment of different 'open' cognitive positions, which are open to self-criticism and can risk by taking free responsibility at the same time. It's obviously that such rationality supposes creation, freedom, the highest mobilization of all personal constructive mental efforts, which are realized, however, in the context of interpersonal work and the process of communication. Both this work and the communication are directed to some cognitive ideal of as wide, complete and deep understanding of the reality as it's possible. They also require a constant ability to take a critic and reflexive position of an outer observer regarding own aims and convictions from the point of view of their correspondence to the reality in which a person is being included and inserted.

Thus, the modern type of scientific rationality broadens the reflexion field over activity. It takes into account the correspondence of the received knowledge about the object not only with features of activity means and operations, but also with value and special structures. The connection between internal scientific purposes and external social values and aims is being explicated.

Scientific perception is considered in the context of social terms of its existence and social consequences as a special part of the community existence, which is determined at every stage of its development by the general state of culture in the given historical epoch, its value orientations and world outlook positions. The historical changeability is comprehended not only from the position of ontological postulates, but according to epistemological ideals and norms. It develops and enriches the content of such categories as 'theory', 'method', 'fact', 'basis', 'explanation', etc.

It's possible to make a conclusion from the above material, that the process of construction of the modern scientific picture of the world causes a special situation of binding in the united system theoretical and experimental researches, applied and fundamental knowledge, intensification of feedforward and feedback among them. Hence, we can observe the intensification of communication processes among principles and presentation of the reality pictures, which are formed in 
different sciences. Thus, object is cognized as a result of organic sciences, which don't have strict differentiating lines. The scientific picture of the world is received as fragments of the integral and general scientific picture of the world.

Such new orientations as non-linearity, irreversibility, non-equilibrium and others are used for the construction of the modern scientific picture of the world. They have been accepted with uncertainty as equitable elements of the conceptual analysis so far. The more extensive new scope of the concept 'perception' includes intuition, uncertainty, heuristics and other pragmatic characteristics, which were not traditional for the classic philosophy, e.g. good, effectiveness. The object sphere is expanded in the new scientific picture of the world due to including such systems in it as 'artificial intellect', 'virtual reality', 'cyborg-relations' which are the results of the scientific and technical progress. Such radical extension of the object sphere takes place in parallel with its radical 'humanization'. And a person is included in the picture of the world not only as its active participant, but as its constituent principle.

Human thinking with its aims and value orientations brings such characteristics in itself, which join the subject content of object. That's why the construction of the modern scientific picture of the world nowadays is possible only from the position of unity of objective and subjective characters. Social and cultural content also penetrates here. Subject and object categories form the system with elements dependent on each other and on the system in general. The ideal of spiritual unity of man and world having been proclaimed since antique times can be found in this system.

\section{Radical Constructivism as Core Idea of the Theory of Self-Organization}

\section{1. 'Cybernatics of Cybernatics' by H. von Foerster}

Let's consider what decision this issue finds in the theory of radical constructivism as according to S.A. Cokolov (2000), "radical constructivism is epistemology of the theory of self-organization and the theory of selforganization is ontology of radical constructivism".

H. von Foerster claimed in his "cybernatics of cybernatics' that there was always the idea of cyclicity in self-organization of any system as it was the process of organization of some organization. He paid attention to 'circularity' of phenomena which took place in cybernatics by means of positive and negative feedbacks of system elements. When such a circulation occured, causa efficientis (initial reason) and causa finalis (final reason) by Aristotle should be understood as a single whole (Foerster 1985). Instead of the 'first-order cybernatics', there appeared the 'second-order cybernatics' that suggested the transformation from cybernatics of observing systems to cybernatics of observed ones. It meant that observer would tend to 'post-objectivity' discovering his features instead of objectivity which didn't take his peculiarities into account. Foerster proved that everything what could be said by observer was said in the 'second-order cybernatics'. So, any observation was impossible without observer. This conclusion meant that observer (a man) didn't reflect the world in such an extent as constructed it. Thus, he couldn't learn the reality. Every observer would construct his own reality and try to learn his own world. In fact, he was alone from epistemological point of view as he observed and constructed the surrounding world on the strength of his cognition abilities and possibilities. One observer's truth would be wrong for another one. As a result, the cognition process got a cyclic character and the purpose of cognition would be in cognition itself.

On the basis of the above it's possible to conclude that the synergy conception is explained differently in compassion with the theory of the 'second-order cybernatics'.

\subsection{Autopoiesis Concept by H. Maturana and F. Varela}

The autopoiesis concept by H. Maturana and F. Varela has an orientation on the research of systems which are closed operationally and can self-reproduce themselves. That's why human brain is considered by them as a system producing the world insulated cognitively. They offer to learn "living systems as a process taking place in the reality, but not to interpret them through the connection with the reality" (Maturana, Varela 1987). Neither living system can be identified separately from its environment. However, the environment can initiate some structural changes of an organism, but can't specify them. According to the theory of the autopoiesis, nervous system is involved in inner cycles of life support. It doesn't have any target in its surrounding as the target is inside the system itself. Hence, a man as 'a living system' doesn't just reflect the world surrounding him, but constructs it in correspondence with his cognitive, existential and social sets. As an autopoietic system, a man progresses independently while broadening his relations with the world. It leads to the appearance of inner and outer relations which form his personal space.

The principle of operational 'insularity' doesn't mean 'closedness' at all. It should be considered as conceding autonomy of living systems, their interaction with the environment and self-development. Self-regulated systems don't control 'exit', but 'entrance'. They function due to the feedback principle. The theory of constructivism suggests that 'entrance' doesn't correspond to the results an outer observer can get. It will be a result of system's perception. This idea explains why living bodies stay stable to the outer impact in spite of their regular contact with the environment. It leads us to the thought that autopoietic systems renew themselves, that's why they are the only product of their organization. Their own organization stays invariant, i.e. it specifies a net of their interactions. 
However, any living body goes through some changes occurring together with the environmental ones. Neither living system can be defined separately from its environment which initiates, but doesn't specify this system's structural changes.

Thus, autopoietic systems have the following features:

(1) operational insularity - self-organization process is possible due to the feedback based on system's inner laws. It's not guided from outside;

(2) informational insularity - any 'outer' influence should be transformed in 'inner' state of brain activity, because such a system can respond only to them;

(3) physical openness - there is an exchange of substances and energy with the environment and its character is defined by autopoietic system.

It's possible to note that constructivism epistemology runs through the autopoiesis concept of living systems as cognitive ones. System's inner state forms subject's idea of the environment. However, there is always an outer observer who could play a role of subject observed in his turn. This process of changing observers is limitless in fact as there can't be 'the last observer', i.e. some exclusive observation system doesn't exist. It means that absolute objective knowledge about the world can't be achieved. So, the rationality of cognition will be in the world constructed by an observer and the theory of constructivism could be considered as the theory of observation systems.

It's interesting to note that synergy principles allow us to learn a man as a complex self-organizing object whose epistemological activity occurs in correspondence with logics of synergetic models. It's possible to conclude after studying the cognition process in the theory of radical constructivism that the achievement of some balance between the reality and the result of subject's cognition activity is impossible in practice. As subject constructs the world, everyone will have his own reality. It means that subject doesn't feel any 'resistance' from the reality. He doesn't see any boundary between his own experience and the reality itself. Application of this idea to the theory of self-organization can lead us to the thought of cognition self-organization by subject (its examples are ideas by $\mathrm{P}$. Watzlawick, J. Piaget). If some knowledge received by subject corresponds to the reality, it means the construct coincidence with the world perceived that can be both subjective and physical (Glasersfeld 1996). Hence, cognition is adaptation (object has got something similar to subject's activity).

\section{3. "Second-Order Observation" Theory by N. Luhmann}

N. Luhmann applied the concept of self-organization to "paradigm alteration in the theory of systems" (Luhmann 1984). He also used it very fruitfully to construct his sociological theory. As a result of this work he made a conclusion that "the idea to apply a self-referent way of work to the theory of social systems is situated in the center (the way of cyclical organization)" (Luhmann 1997). He also developed constructivism concepts in the epistemology during this work.

His theoretical reflection led to the appearance of the "second-order observation" theory. Luhmann said that "our look catches both sides of one object simultaneously" (Luhmann 1992). The concept of observation is very abstract for him. As a result, there arises a question if this observation "belongs to a man or a machine, brain, consciousness or a system of communication" (Luhmann 1991). At the same time a question about "differences in observers' equipment status" is excluded (Luhmann 1991). He explains "differentiating and marking" observers as a way to use general mechanisms of "surplus production and selection" or "destabilization and suppression" which are connected with the evolution of self-organizing system.

Thus, an observation can have a character of a very complex system. Cells, organisms, societies, systems of artificial intellect are able to play observers' role. The second-order observation or observation of observation is different because of the circumstances of its observation, if an observer himself has performed it or someone or something has been looking after him. According to Luhmann's theory, observer can't see himself, i.e. he isn't able to make out himself and his observation. At the same time another observer can see him. He has an ability to see the observer and what is being observed. Luhmann defines this process as the second-order observation (autoreflection idea). According to him, these conditions lie in the foundation of epistemology.

Luhmann tries to avoid that typical hierarchy that is often used in reflection when it's necessary, e.g., to make a difference between object's plane and metaplane or between the transcendental and the empiric. It leads to exclusion of any further observations. The idea of 'observation' allows us to avoid the epistemological traditional terminology, in particular, subject-object scheme. For example, it's possible to consider relationships between a system and its environment while observing. Hence, Luhmann's theory corresponds to the ideas of radical constructivism representatives. According to it, a system can't exceed its limits and is involved only in its own definitions. "Countless own systems operate inside a man as a condition of his life. They define the operations they implement by means of their own structures despite they're dependent on each other" (Luhmann 1988). It gives an idea that the world of observation is created the same way as any other system activities.

So, an answer on the ontological questions: "what is it?" and "how is it?" will depend on a definite observer restricted by the world of his observation. We can say he is similar to some empiric value that stipulates selecting him as an object by other observers. This constructivism concept looks like more sociological than philosophical. The author makes a conclusion that man constructs a society not accidentally, according to his desires, but in coevolution with the general development of social structure. This process can be explained by human mental abilities to 
distribute and recombine a structure in general that is necessary while describing differentiated functional systems of the modern society. It is obvious that subject and the environment which he acts in are interconnected constructively and they go through mutual formation in the process of his activity.

The above analysis demonstrates that Luhmann's ideas are rather abstract. He substitutes many concepts accepted generally and created by conceptual frames of human thinking. For example, this remark could be applied to Luhmann's replacement of realistic epistemology by constructivism as a result of replacing the traditional epistemology by 'the theory of observations'. Thus, observation in his concept is something more than just perception. It is a type of system operations. In this case, describing the world will be a constituent part of the reality, one of its systems.

\subsection{Constructive Realism by F. Wallner}

This approach doesn't completely correspond to the current level of modern science development. I.Z. Shishkov notes that "modern science isn't only object-oriented, but self-reflexive" (Shishkov 2003). I think the theory of constructive realism by $\mathrm{F}$. Wallner satisfies this criterion largely. It can be called a scientific and cognitive program that finishes constructive understanding of natural sciences and tries to renew a search of sensible life connections by means of interdisciplinary interaction. Despite the name 'constructive realism' supposes a realistic version, Wallner's position in epistemological and theoretical aspects is constructive one completely. He makes a difference "between the reality as the world behind our cognitive operations, the world which we live in... and the reality as the world which could be obtained only by cognition" (Wallner 1993). Approach of natural sciences "lies behind ordinary reflection of the reality; it produces relations much more" (Wallner 1993). According to him, natural sciences don't reflect the world, but give an idea about a number of 'microworlds' which are "functional integrities correlated with a specific data set" (Wallner 1994). Structure of any microworld should satisfy only some definite criteria chosen by scientists.

According to Wallner, a scientist, especially a naturalist, always specializes in a definite field and uses special tools. The main attention isn't paid to circumstances being used to comprehend this field in the interdisciplinary context, but technical opportunities of essential relations helping to answer a raised question. He recognizes an important role of scientific philosophy calling for "the old European idea of educational meaning of science" (Wallner 1994). In his books Wallner offers to apply interdisciplinary methods calling them 'alienation'. A scientist calls for 'alienation' if his theory has another structure than the existing methodic potential and is inserted into an absolutely strange context (e.g., physical theory into sociological context). It's possible to conclude from Wallner's theory that a scientist understands constructive and cognitive features in accordance with definite methods and the initial relevant context of natural scientific theory.

J. Gibson's research of human perception influenced the formation of the above position in epistemology and social sciences (Gibson 1979). Its importance is in the author's consideration of perception not as a consciousness phenomenon, but as an event of the reality, a necessary component of life. According to him, the sharp opposition of 'inner' and 'outer' appeared after Descartes disappears. So, cognition together with its constructions begins dealing with the reality.

\section{Some Important Conclusions}

The analysis of different constructivism concepts in this article demonstrates that the theory of constructive realism removes the confrontation of constructivism and realism. Subject plays an important part in perception constructing it to a certain extent and processing sensor data by definite rules and standards in this theory.

V.A. Lectorsky points out that "any construction supposes the reality which it exists in, reveals and tries to transform. On the other hand, subject reveals and actualizes the reality only through its constructive activity" (Lectorsky 2009). The 'constructed' object doesn't mean a fictitious construct. For example, any piece of furniture surrounding us has been constructed by man and it is a physical reality. All social institutes created by mankind are the reality although they're ideal constructions in a certain sense. If we consider the subjective world of man, it's possible to conclude that, to a large degree, it is also an ideal construct exposed to theoretical and experimental researches. Therefore, the reality could be examined as multilayer and multilevel. Different levels aren't reduced to each other, but there is some dependence among them. Their ways of existence are different, that's why it is allowed to suggest the idea of 'different worlds' existence. Each of these 'worlds' is real and connected with the others. In such case, subjective world is also the reality, but different from the physical one. So, the adequate cognition process is possible while taking all these components into consideration.

“Any border between 'inner' (i.e. taking place inside subject of cognition) and 'outer' (i.e. its environment) is removed" in epistemology nowadays (Lectorsky 2005). This idea means the reality isn't just subject's construction.

Nowadays it's supposed in epistemology that subject of rational and cognitive activities acts on the basis of theoretical schemes and models, methodological rules, empiric information, logic norms of reasoning. They are used as a material to take a decision concerning a mode of action for the current problem. Such a choice from a number of alternatives and a range of possibilities is stipulated by subject's constructive thinking and open for future revision. It's possible to conclude subject isn't a closed system, but supposes openness to the world. Therefore, a scientific model of the reality becomes a result 
of interaction of subject's activity with the reality. This result corresponds to the theory of constructive realism completely.

In contrast with the classic theory directed to the statement of some fact, the cognition process from the synergetic point of view is an act of constructive thinking open for further criticism. Hence, the cognition process is included into the reality, but not excluded from it. It is the aspect in the communication theory that promotes getting a rational knowledge about the reality by subject.

\section{References}

[1] Cokolov, Sergey A. 2000. Discourse of radical constructivism. Traditions of scepticism in modern philosophy and epistemology. Munich: Phren.

[2] Encyclopedia of epistemology and philosophy of science. 2009. Moscow: Canon+.

[3] Foerster, Heinz von. 1985. Sicht und Einsicht. Versuche zu einer operativen Erkenntnistheorie. Braunschweig, Wiesbaden: Vieweg.

[4] Gibson, James J. 1979. The ecological approach to visual perception. Boston: Houghton Mifflin.

[5] Glasersfeld, Ernst von. 1996. Radical constructivism: a way of knowing and learning. London: Falmer Press.

[6] Gurevich, Pavel S. 1993. Anthropological Renaissance. In Man's phenomenon: Anthology. 3-23. Moscow: Higher School.

[7] Kasavin, Ilya T. 2008. Constructivism as idea and direction. In Constructivism in epistemology. ed. V.A. Lectorsky. 6372. Moscow: IPhRAS.

[8] Lectorsky, Vladislav A. 2005. Kant, radical constructivism and constructive realism in epistemology. Questions of Philosophy 8: 11-21.
[9] Lectorsky, Vladislav A. 2009. Realism, antirealism, constructivism and constructive realism in modern epistemology and science. In Constructivism approach in epistemology and social sciences. ed. Vladislav A. Lectorsky. 4-40. Moscow: Canon+, ROOI Rehabilitation.

[10] Luhmann, Niklas. 1984. Soziale Systeme. Frankfurt am Main: Suhrkamp Verlag.

[11] Luhmann, Niklas. 1988. Erkenntnis als Konstruktion. Bern: Benteli.

[12] Luhmann, Niklas. 1991. Soziologie des Risikos. Berlin, New York: Walter de Gruyter.

[13] Luhmann, Niklas. 1992. Beobachtung der Moderne. Opladen: Westdeutscher Verlag.

[14] Luhmann, Niklas. 1997. Die Gesellschaft der Gesellschaft. Bd.1. Frankfurt am Main: Suhrkamp Verlag.

[15] Maturana, Humberto and Varela, Francisco. 1987. Der Baum der Erkenntnis: Die biologischen Wurzeln des menschlichen Erkennens. Bern, Munich: Scherz.

[16] Ogurcov, Anatoly P. 2008. From normative Mind to communicative rationality. In Etos of science. Ed. L.P. KIyaschenko, E.Z. Mirskaya.48-86. Moscow: ACADEMIA.

[17] Prigogine Ilya, Stengers Isabelle. 2001. Order out of chaos: Man's new dialogue with nature. Moscow: Editorial URSS.

[18] Shishkov, Ivan Z. 2003. Searching for new rationality: Philosophy of critical mind. Moscow: Editorial URSS.

[19] Wallner, Fritz G. 1993. Der Konstruktive Realismus: Theorie eines neuen Paradigmas? In Grenzziehungen zum Konstruktiven Realismus. ed. G. Wallner, J. Schimmer und M. Gostazza. 12-21. Wien: WUV Universitätsverlag.

[20] Wallner, Fritz G. 1994. Die neue Wiener Schule des Konstruktiven Realismus. In Grenzziehungen zum Konstruktiven Realismus. ed. G. Wallner, J. Schimmer und M. Gostazza. 22-35. Wien: WUV Universitätsverlag. 